\title{
Quantifying differential gene connectivity between disease states for objective identification of disease-relevant genes
}

\author{
Jen-hwa Chu ${ }^{1 *}$, Ross Lazarus ${ }^{1}$, Vincent J Carey ${ }^{1,3}$ and Benjamin A Raby ${ }^{1,2,3}$
}

\begin{abstract}
Background: Network modeling of whole transcriptome expression data enables characterization of complex epistatic (gene-gene) interactions that underlie cellular functions. Though numerous methods have been proposed and successfully implemented to develop these networks, there are no formal methods for comparing differences in network connectivity patterns as a function of phenotypic trait.
\end{abstract}

Results: Here we describe a novel approach for quantifying the differences in gene-gene connectivity patterns across disease states based on Graphical Gaussian Models (GGMs). We compare the posterior probabilities of connectivity for each gene pair across two disease states, expressed as a posterior odds-ratio (postOR) for each pair, which can be used to identify network components most relevant to disease status. The method can also be generalized to model differential gene connectivity patterns within previously defined gene sets, gene networks and pathways. We demonstrate that the GGM method reliably detects differences in network connectivity patterns in datasets of varying sample size. Applying this method to two independent breast cancer expression data sets, we identified numerous reproducible differences in network connectivity across histological grades of breast cancer, including several published gene sets and pathways. Most notably, our model identified two gene hubs (MMP12 and CXCL13) that each exhibited differential connectivity to more than 30 transcripts in both datasets. Both genes have been previously implicated in breast cancer pathobiology, but themselves are not differentially expressed by histologic grade in either dataset, and would thus have not been identified using traditional differential gene expression testing approaches. In addition, 16 curated gene sets demonstrated significant differential connectivity in both data sets, including the matrix metalloproteinases, PPAR alpha sequence targets, and the PUFA synthesis pathway.

Conclusions: Our results suggest that GGM can be used to formally evaluate differences in global interactome connectivity across disease states, and can serve as a powerful tool for exploring the molecular events that contribute to disease at a systems level.

\section{Background}

Network and pathway models have been frequently used to describe complex interaction patterns of genes and other types of molecules, and there is increasing recognition that such networks will facilitate a more clear understanding of cellular physiology [1]. Developed using global expression [2], proteomic [3,4], or metabolic [5] measures, the models can be used to characterize the

\footnotetext{
* Correspondence: stjhc@channing.harvard.edu

${ }^{1}$ Channing Laboratory, Brigham and Women's Hospital, Harvard Medical School, Boston MA 02115, USA

Full list of author information is available at the end of the article
}

patterns of interaction (gene-gene, gene-protein, etc) that underlie cellular states. Such models have been used to define the complex pathobiology of numerous cancer types [6-8], neurological conditions [9], and metabolic disorders [10]. More recently, models constructed through integration of genotype and expression data have been used to identify disease-susceptibility loci that alter network dynamics [11,12].

Though network models are fairly easy to visualize using graphs, direct comparison of two models (for example, transcriptome networks across disease states), and quantitative measurement of the differences
C Biomed Central

(c) 2011 Chu et al; licensee BioMed Central Ltd. This is an Open Access article distributed under the terms of the Creative Commons Attribution License (http://creativecommons.org/licenses/by/2.0), which permits unrestricted use, distribution, and reproduction in any medium, provided the original work is properly cited. 
between networks, remains challenging. In recent years there have been growing literature of methodology for such comparisons [13], either for a global scale estimation of overall network similarity [14-16], or for measures of local difference in connectivity for nodes or modules in the network [17-19]. Among the many methods used to infer gene networks are Gaussian Graphical models (GGM) [20-23], including the empirical Bayes methods for fitting Gaussian graphical models [24], which performs well in inferring large- $p$ small- $n$ gene networks. As a probabilistic method, GGM provides posterior probabilities of gene-gene interaction for each edge in the network, a quantifiable measure of interaction that incorporates the uncertainty of the model. We recently [25] applied the method to build an integrative network based on multiple data sources (i.e. SNP genotypes and gene expression data). We now extend this method to integrate clinical phenotypes, such as disease status, in order to facilitate identification of network modules whose connectivity patterns differ by disease status. Our approach enables direct comparison of two co-expression networks and objective identification of network components that consistently exhibit differential connectivity patterns across disease states. For simplicity we will only consider dichotomous phenotypes, though this method could be extended to categorical or continuous traits as well.

\section{Methods}

First we describe the GGM for gene expression data. The expression data matrix $Y$ observed here has $G$ genes and $N$ samples, and the model follows [24] and [25], where $Y$ follows a multivariate normal distribution:

$$
Y_{i}=\left(\gamma_{1 i}, \ldots . \gamma_{G i}\right)^{T} \sim N_{G}\left(\mu_{Y}, \Sigma_{Y}\right), \quad i=1, \ldots N,
$$

where $y_{j i}$ represents the expression observation for $j$ th gene in the $i$ th sample, $\mu$ is the mean vector and $\Sigma$ is the covariance matrix. The covariance matrix $\Sigma_{Y}$ and the partial correlation matrix $\Pi$ for $Y$ are estimated based on the shrinkage estimation described in [26]. The partial correlation $\Pi_{j k}$ here represents the conditional dependency between gene $j$ and gene $k$, i.e, $\Pi_{j k}=0$ if the two genes are independent conditional on all other expression values and $\Pi_{j k} \neq 0$ if they are conditionally correlated. Therefore the network estimation problem is reduced to a sequence of $G(G-1) / 2$ hypothesis testing problem for $\Pi_{j k}=0$. Following the mixed model approach in [24] we can calculate the empirical posterior probability that $\Pi_{j k}$ $\neq 0$ for each pair of genes (panel (a) and (b) in Figure 1). Figure 2 shows an example of the distribution of partial correlations and their corresponding posterior probabilities. The partial correlation coefficient $\Pi_{j k}$ follows a normal distribution (panel a), but the mixed prior, which assumes that the majority of the gene pairs are not connected, effectively shrinks most of the posterior probabilities toward zero (panel b). We can see in panel (c) as $\Pi_{j k}$ grows away from zero the probability of a significant edge quickly approaches 1 and the narrow U-shape demonstrates the ability to identify significant edges for relatively small absolute values of partial correlation coefficients (e.g. 0.04-0.05).

Suppose we have the estimation of networks from two different disease groups. If we consider the posterior probability of an edge as a frequency, as if we could actually observe the proportion of samples in the group, then for the two disease groups $C$ and $D$ we can calculate the posterior odds ratio (postOR) for each edge:

$$
\operatorname{postOR}_{j k}=\frac{\hat{p}_{j k}^{C} /\left(1-\hat{p}_{j k}^{C}\right)}{\hat{p}_{j k}^{D} /\left(1-\hat{p}_{j k}^{D}\right)} .
$$

where $\hat{p}_{j k}^{C}$ and $\hat{p}_{j k}^{D}$ are the posterior probability estimates for the event that an edge exists between gene $j$ and gene $k$, in groups $\mathrm{C}$ and $\mathrm{D}$, respectively. If $\hat{p}_{j k}^{\mathrm{C}}$ and/ or $\hat{p}_{j k}^{D}$ are zero, we assign them a very small number on the same scale as the smallest non-zero posterior probability to make sure all odds ratios are well-defined. The posterior odds ratios between the disease groups provide a quantitative measure for difference between network connectivity, and the parts of the network where the postORs differ from 1 are likely the parts most relevant to the disease state (panel (c) in Figure 1). Panel (d) in Figure 2 shows a histogram of the log posterior odds ratio, with most of the edges concentrated around zero and relatively few of them way out in the tails, which represent the edges associated with the disease states. The gap from around \pm 5 to \pm 30 roughly corresponds to the sharp climb in the posterior probability seen from panel (c) in Figure 2. This pattern has been observed in all data sets that we have analyzed, though the scales in which the extreme observations fall may vary depending on the sample size and the number of genes in the network. As the sample size increases relative to the number of genes, we observe more extreme values of log postORs, in some cases going up to \pm 50 or 60 .

The idea of using posterior odds ratios to quantify differential connectivity can also be generalized to model more focused differential gene connectivity patterns within previously defined sets of genes, including experimentally derived gene networks and canonical pathways. For example, for a given set of genes $A$, we define the differential connectivity score (DC score) as the average absolute differential connectivity, measured by difference in log posterior probability, for all edges comprising set $A$ : 

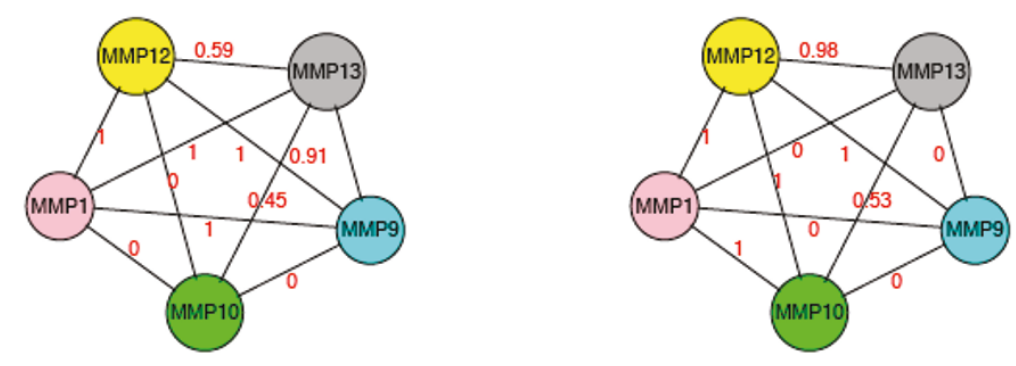

(c) Log Posterior Odds Ratios

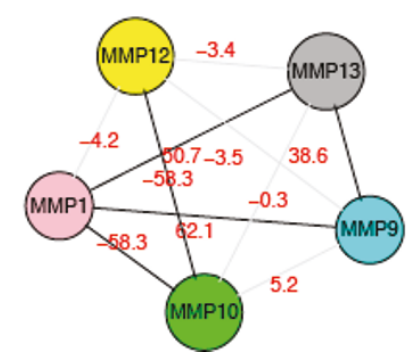

Figure 1 Determining the posterior odds ratio (postOR). Gene network for five genes in the matrix metalloproteinases network determined separately in grade 1 breast cancer samples (a) and grade 3 samples (b). The posterior probabilities of gene-gene connection (in red) determined by GGM, support true edges in both tumor grades between MMP1 and MMP12, and between MMP12 and MMP9 (postProb 1); and a true edge between MMP12 and MMP10 in grade 3 but not grade 1. The log posterior odds ratios of the probabilities (in red in panel c) quantify the magnitude of difference in connectivity across disease states. Data derived from GEO series 2990 [28]. See the results section for detail of the breast cancer data analysis.

$$
\text { DC Score }_{A}=\frac{\sum_{j, k \in A}\left\|\log \hat{p}_{j k}^{C}-\log \hat{p}_{j k}^{D}\right\|}{\sum I(j, k \in A)},
$$

which is a good approximation of the average postORs for all edges in the set, as most of the posterior probabilities $\hat{p}_{j k}^{C}, \hat{p}_{j k}^{D}$ are close to zero. This gives a reasonable measure of the overall differential connectivity for each gene set.

\section{Results}

\section{Simulation Study}

To assess the theoretical performance of our approach, we performed a series of simulation studies. For each simulation study we first generate two partial correlation matrices representing networks observed in two groups of samples (i.e. "cases" and "controls"), and then generate synthetic expression data sets from them. We then attempt to recover the network using GGM and calculate the postORs for all pairs of genes. To simulate networks most closely resembling real world network data, we set out to develop a set of relatively sparse networks with few strong connections. When generating the partial correlation matrices for the "case" network we therefore follow the same approach in [25], whereby we estimate a connectivity network using an expression dataset generated from peripheral blood CD4+ lymphocytes [25], take the top G genes with the highest correlation, retain correlation coefficients of the top $q$ significant edges and shrink all remaining correlation coefficients to zero. We take $\mathrm{G}=100$ and $\mathrm{q}=77$ in our simulation study, which corresponds to about $1.5 \%$ of all possible edges (all with posterior probability over 0.95). The "control" networks are from the null model, where the expression data are generated from an independent multivariate distribution and none of the genes are connected. We simulate the expression data with 200 samples in each group and repeat the entire procedure 10 times.

The left panels (a) and (b) in Figure 3 show the histogram of the log posterior odds ratios for all edges (panel 
(a)

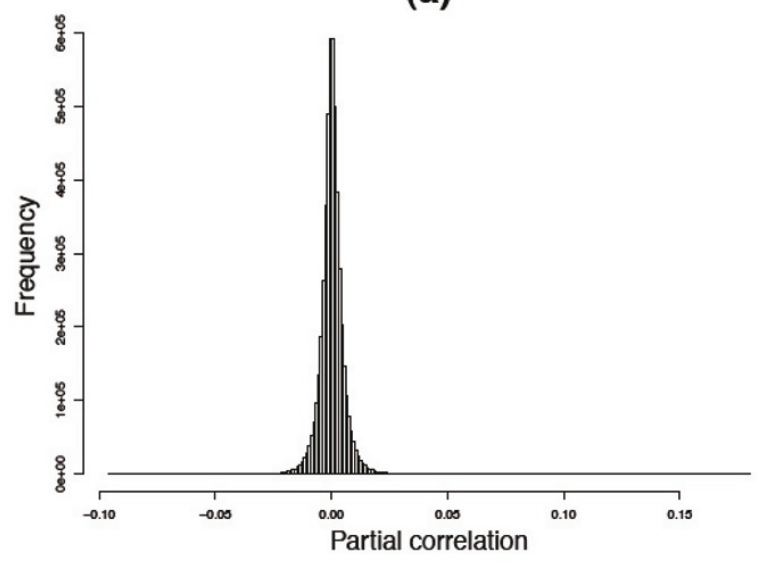

(c)

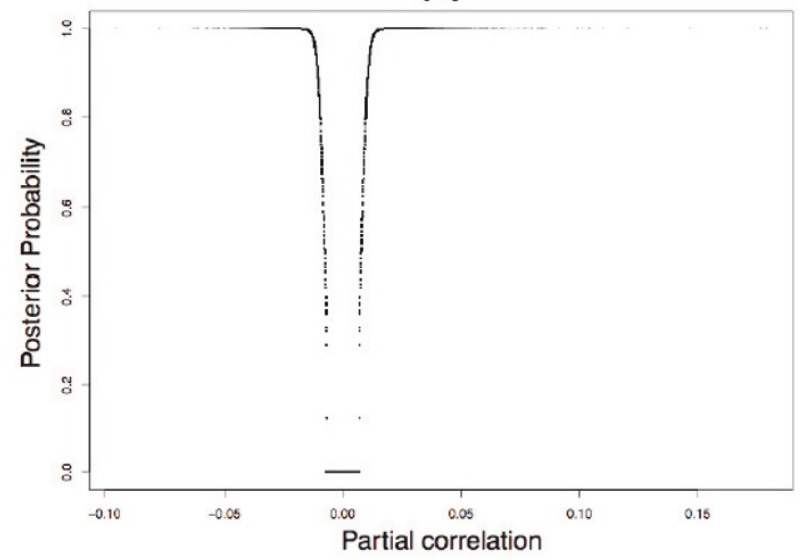

(b)

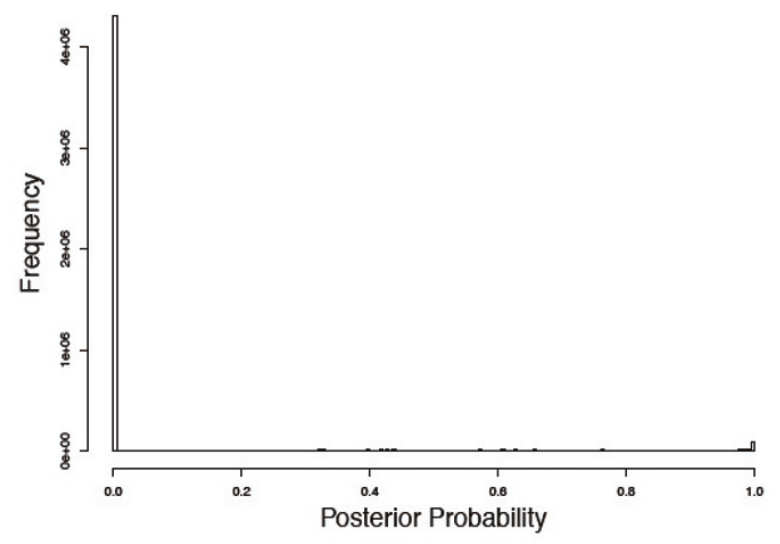

(d)

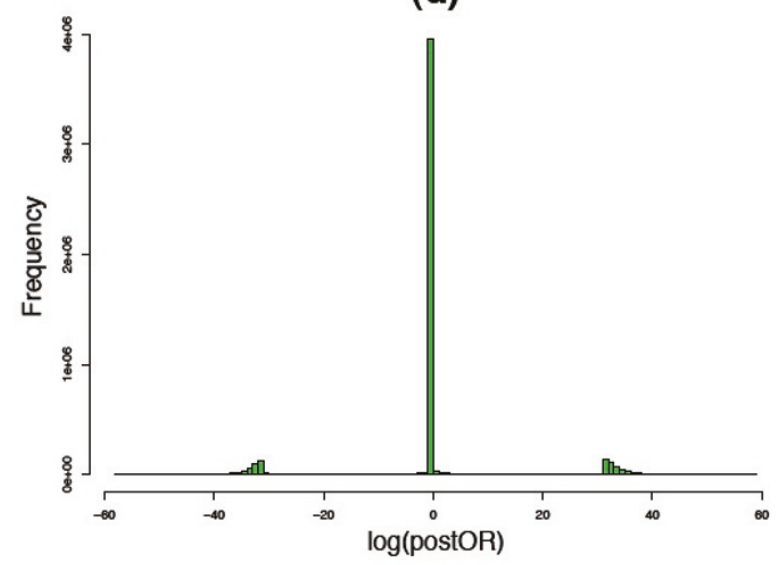

Figure 2 An example of partial correlations, posterior probabilities and log odds ratios. (a)Histogram of partial correlation. (b)Histogram of posterior probabilities. (c) The distribution of partial correlations and their corresponding posterior probabilities. (d)Histograms of log odds ratios. Data generated using Illumina HumanRef8 expression data from peripheral blood CD4+ lymphocytes [25].

a) and for the $1.5 \%$ edges that were truly differentiated (panel b). From the right hand side of the panel (a) we see that the log posterior odds ratios from the null edges goes as high as 40 . Therefore we take \pm 40 as the threshold, which gives $72.34 \%$ sensitivity and $99.90 \%$ specificity for detection of a differentially connected edge. Though we miss a considerable proportion of true edges (shaded in grey in panel b), the very high specificity is particularly encouraging, as it suggests that positive findings are very reliable. Note that even a small reduction in specificity (for example, a $1 \%$ increase in the false positive rate) would result in identification of the thousands of spurious differential connections, given the enormous number of pairwise comparisons in any given genome-wide analysis. It is therefore essential to maintain high specificity in this context. We note that for smaller datasets (a simulation with 50 cases and controls), though sensitivity drops considerably (15.06\% in our simulation using a cutoff of -40 posterior odds), the high specificity is retained (99.95\%). We also considered more realistic scenarios, including situations where both networks (the "cases" and the "controls") contain positive edges and where sample size is uneven between groups, and found very comparable results. For example, right panels (c) and (d) in Figure 3 show an example of unbalanced data, where one set has 200 samples and the other has 50 , containing $2.5 \%$ and $5 \%$ true positive edges, respectively. Using the same threshold of posterior odds at -40 the sensitivity is $40.47 \%$ and specificity is 99.65\%. Figure 4 shows the ROC curves from all three scenarios considered. We can see that the power varies depending on the sample size and number of variables, but the specificity always stays close to $100 \%$, and the absolute postORs from the null distribution rarely exceed 40. Therefore, we can conclude that in realistic scenarios, though we are not able to identify all truly 
(a) Histogram of log postOR, all edges

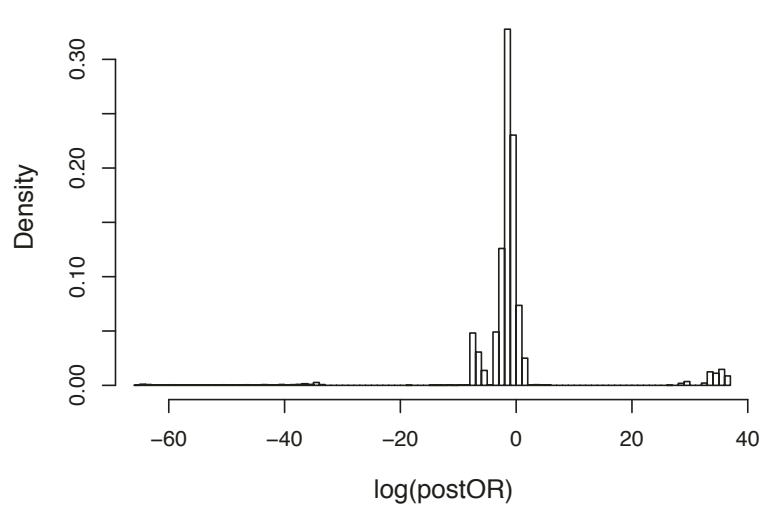

(b) Histogram of log postOR, true positives

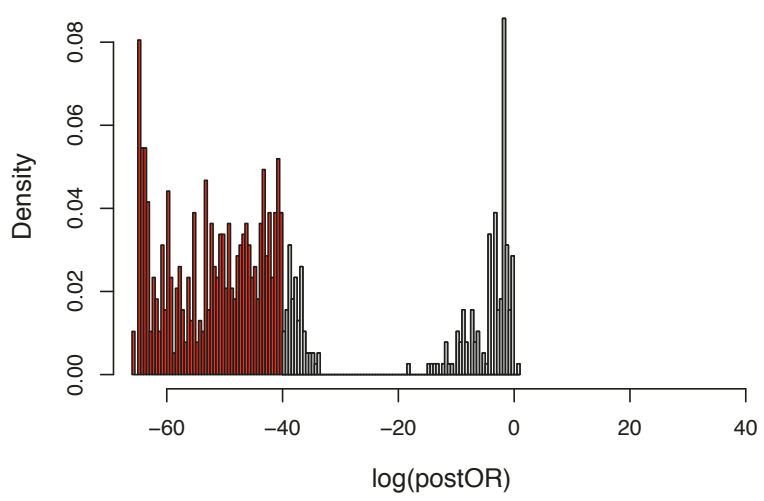

(c) Histogram of log postOR, all edges, imbalanced data

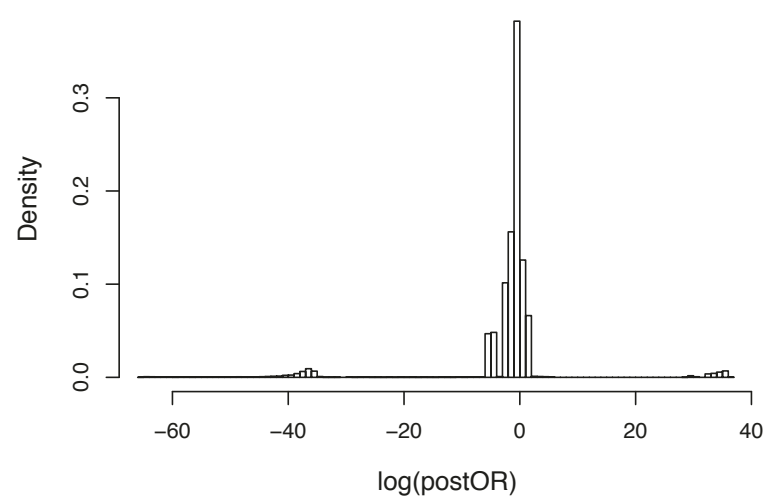

(d) Histogram of log postOR, true positives, imbalanced data

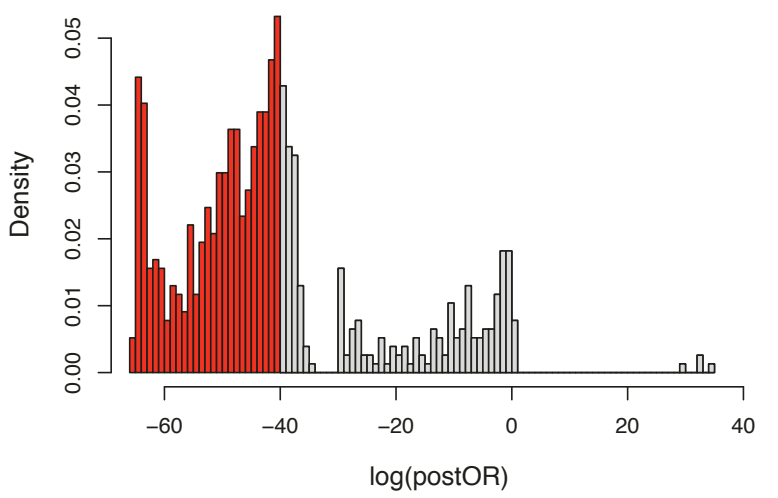

Figure 3 Histograms of log odds ratios in the simulation studies. All edges (panel (a) with $N=200$ for both data sets and panel (c) for unbalanced samples $(N=200 / 50)$ ) and true positive edges (i.e. truly differentially connected between disease states, panel (b) for $N=200$ and (d) for unbalanced samples). Red shaded results in panel (b) and (d) denote truly differentially connected edges that are not detected at cutoff of $\log O R=-40$ (i.e. false negatives).

differentially connected edges, those edges that are declared as differentially connected between states are very likely to be true findings.

Alternatively, we could compare the partial correlations or Pearson correlations between the "cases" and "controls", as shown in Figure 5. In both cases the truly differentially connected edges seem well-separated from the unconnected edges (panel a-b), though from the histogram of the z-statistics (panel c-f) we can see that the true positive edges from partial correlations separate better (have less overlapping with the true negative edges) than the Pearson correlations, which are routinely used to infer gene networks $[18,27]$. Notice for the correlation coefficients we still need to apply arbitrary thresholds [13], as we do not have repeated measurement for the correlations for each individual edge. Compared to Figure 3 we can see that the postORs from the empirical Bayes method, which takes into consideration the sparsity of real gene network, allow us to effectively separate the truly differentially connected edges from others.

\section{Breast Cancer Study}

We now demonstrate the application of our method to real data sets. The main results will be focused on the comparison between two independent gene expression data sets from breast cancer tissues of varying histological grade available through the Gene Expression Omnibus (GEO series GSE2990 and GSE6532). The GSE2990 series consists of Affymetrix Human Genome U133A Array data for 189 breast tumor samples from the National Cancer Institute database [28], from which we selected 100 estrogen receptor-positive $(E R+)$ samples with histological grades $1(\mathrm{n}=61)$ and $3(\mathrm{n}=39)$. The GSE6532 series contains several independent validation sets generated using Affymetrix U133PLUS2 GeneChips and described in [29], from which we used the 33 samples from Guy's Hospital, UK (17 grade 1 and 16 grade 


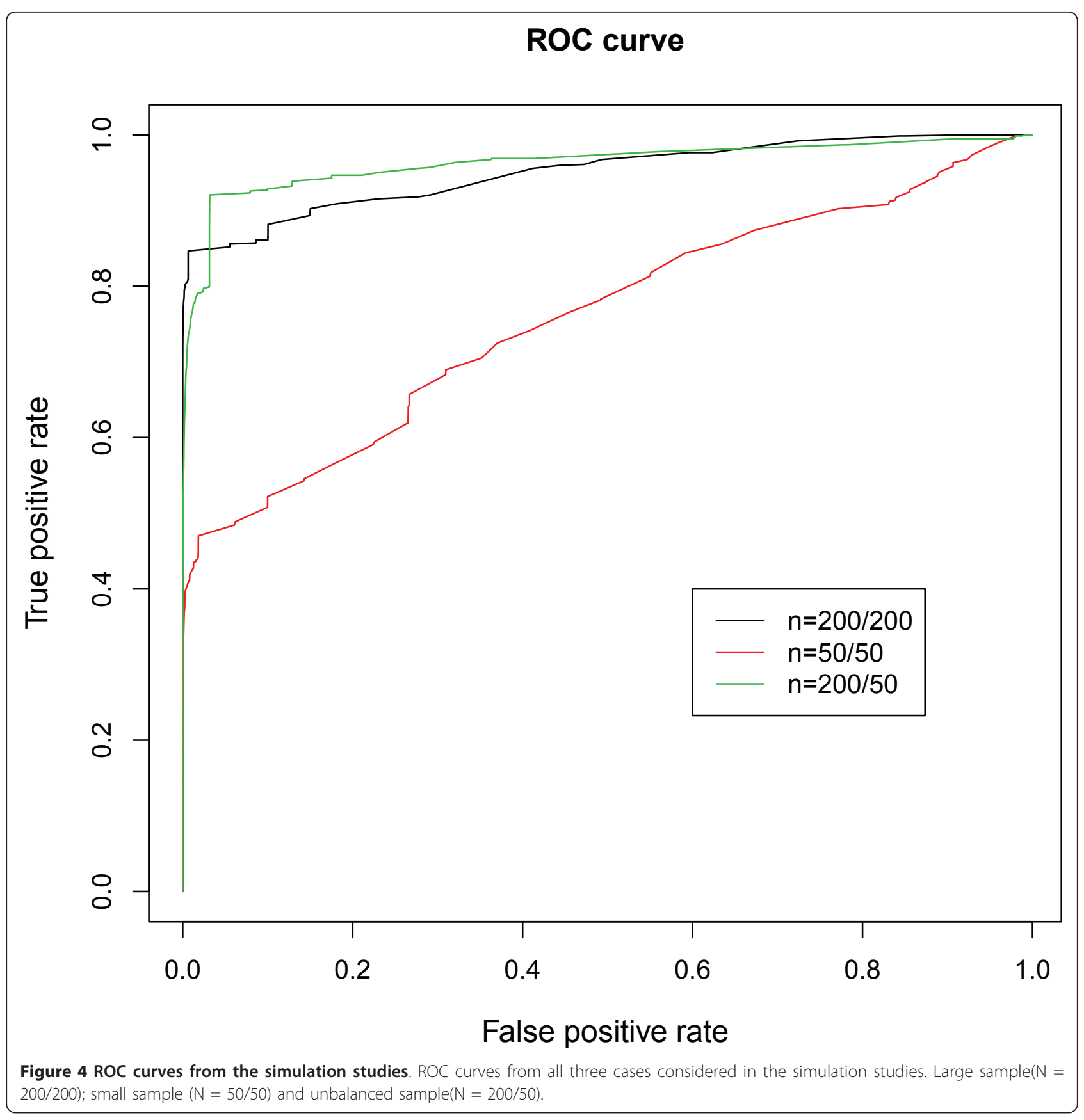

3). These data sets were selected based on sample sizes and availability of clinical phenotypes. Using the $\mathrm{R}$ package genefilter[30], we applied the non-specific gene ltering [31] on both data sets. The resultant data set consisted of 1,445 RefSeq-annotated genes with interquartile ranges (IQR) in the upper $50 \%$ for both data sets.

We applied our method sequentially to define, in each dataset, the differences in network connectivity patterns observed across breast cancers of different histological grades. The two datasets were analyzed separately to enable unbiased evaluation of the reproducibility of findings by our method when applied to biologically independent datasets. We observe a similar pattern to those seen in the simulation studies, with most edges concentrated around zero and relatively few in the extremes. Focusing on the edges with extreme postOR probabilities of differential connectivity between grades (Empirical p-values $<0.001$ based on permutation), we found significant overlap across studies. When considering genes exhibiting high degrees of connectivity - so-called hubs [1] defined as genes with at least 30 independent 


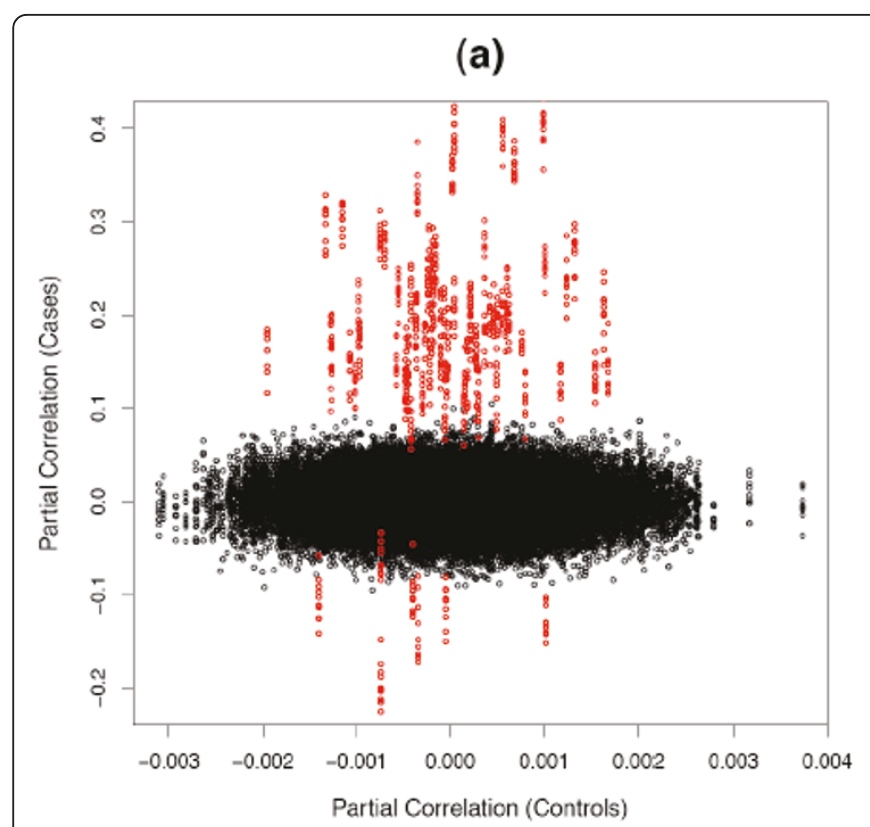

(c)

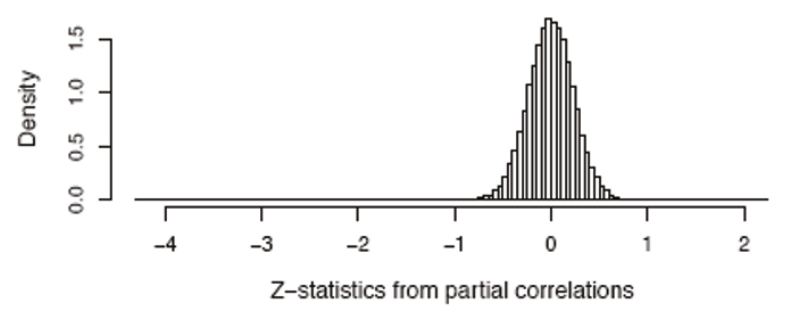

(e)

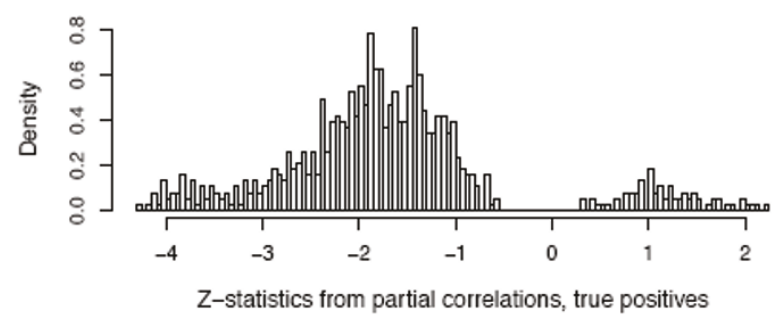

(b)

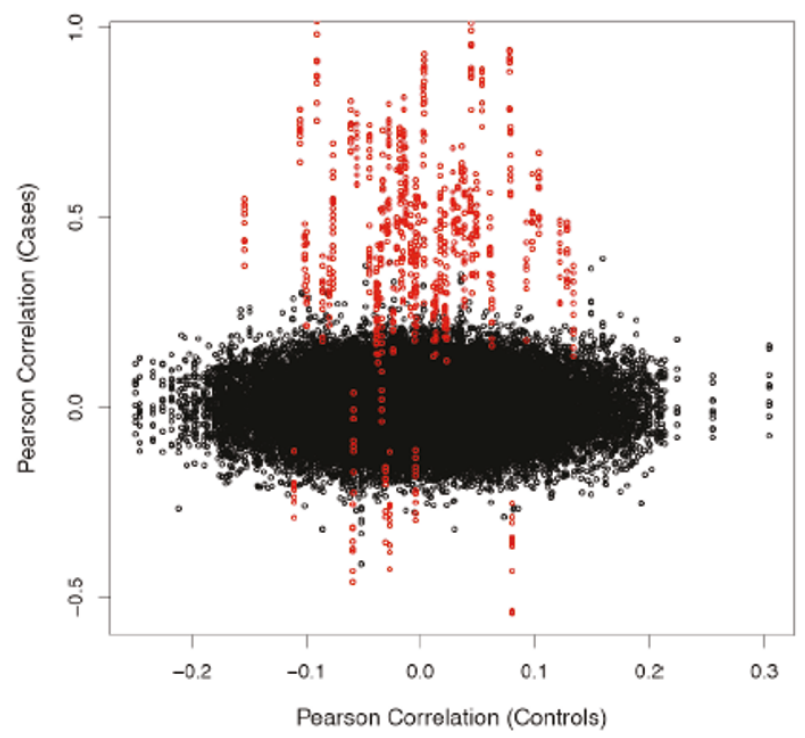

(d)

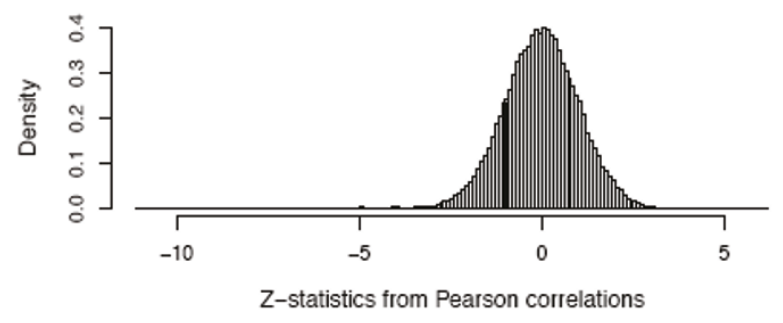

(f)

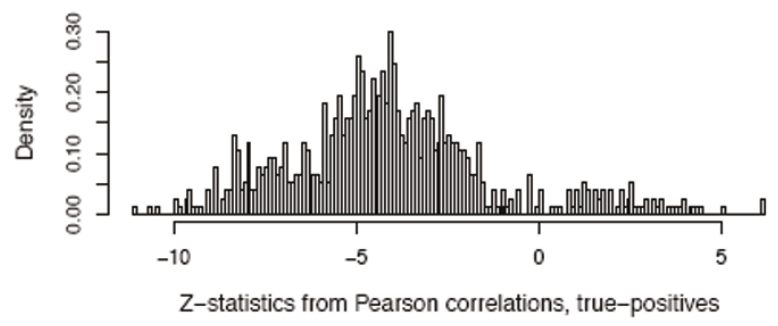

Figure 5 Partial correlations and Pearson correlations. Panel (a-b) show the distribution of Fisher-transformed partial correlation (a) and Pearson correlation coefficients (b) from the simulated "case" and "control" data sets. The red dots represents the differentially connected edges. Panel (c-f) show the histograms of z-statistics $\left\|z_{j i c}-z_{i j d}\right\| / \sqrt{\frac{1}{n_{c}-3}+\frac{1}{n_{d}-3}}$, where $z_{i j c}$ and $z_{i j d}$ are the Fisher-transformed correlation coefficients from the "case" and "control" data sets, respectively. Panel (c-d) are for all edges and panel (e-f) are for the truly differentially connected edges only.

edges - 10 of 33 hubs demonstrating differential connectivity patterns in dataset GSE2990 were also observed in the second dataset GSE6532 (Fisher's exact test, p-value $\left.=1.5 \times 10^{-5}\right)$. This high degree of overlap between two independent data sets suggests that the observed differential network connectivity patterns are a reproducible property of complex biological processes such as cancer progression.
We next examined the gene content of the replicated hub genes demonstrating grade-dependent differences in network connectivity, and found that in all but one case (DHRS2), these hub genes have all been previously characterized in expression studies of breast cancer, with many being implicated as critical regulators or markers of metastatic potential and tumor progression (Table 1). That nearly all the identified genes have been previously 
Table 1 Hub list for breast cancer study (GSE2990 and GSE6532) histological grade 1 and 3

\begin{tabular}{|c|c|c|}
\hline Gene & Frequency & Prior evidence for role in breast cancer biology \\
\hline DHRS2 & $55 / 46$ & $\begin{array}{l}\text { Up-regulated in endometrial cancer by the inducer of myometrial infiltration ERM/ETV5 [55]; Protective role against oxidative- } \\
\text { stress induced apoptosis in endometrial cancer [55]; Down-regulated in ovarian tumors following cisplatin treatment [32] }\end{array}$ \\
\hline CXCL13 & $30 / 45$ & Overexpression in breast cancer tumor tissue, with elevated blood serum levels in patients with metastatic disease [56] \\
\hline AGTR1 & $36 / 42$ & $\begin{array}{l}\text { Overexpressed in subset of estrogen-receptor positive breast cancer; Ectopic overexpression confers a highly invasive } \\
\text { phenotype in primary mammary epithelial cells; AGTR1-positive tumor growth reduced by } 30 \% \text { with receptor blockade in } \\
\text { xenograft model [54] }\end{array}$ \\
\hline KRT15 & $34 / 42$ & $\begin{array}{l}\text { Expressed in breast cancer tissue compared to normal breast tissue [57]; Expression associated with increased risk of post- } \\
\text { operative breast cancer recurrence [58] }\end{array}$ \\
\hline SCGB2A1 & $38 / 49$ & Overexpressed in breast cancer tissue [59]; Associated with mammary gland proliferation and terminal differentiation [60] \\
\hline MMP12 & $31 / 43$ & Breast tumor transfection of MMP12 reduced endothelial cell invasion and capillary tube formation [50] \\
\hline PDZK1 & $47 / 46$ & $\begin{array}{l}\text { Estrogen-regulated gene expressed in hormone-responsive breast cancer [61]; Correlated with estrogen receptor phenotype } \\
\text { [62]; Suppressed with tamoxifen and aromatase inhibitors [63] }\end{array}$ \\
\hline BEX1 & $42 / 54$ & $\begin{array}{l}\text { BEX2 is overexpressed in a subset of primary breast cancers and mediates nerve growth factor/nuclear factor-kappaB } \\
\text { inhibition of apoptosis in breast cancer cell lines. [64] }\end{array}$ \\
\hline S100A8 & $38 / 42$ & $\begin{array}{l}\text { siRNA-mediated knockdown of S100A8/A9 expression significantly reduced H-Ras-induced invasion/migration; Induction } \\
\text { confers the invasive/migratory phenotype [52]; Immunopositivity correlates with mitotic activity, MIB-1 index, HER2 } \\
\text { overexpression, node metastasis, and poor prognosis [65]; Associated with transformation and progression of breast cancer } \\
\text { cells which is reversed by treatment with silencing inhibitors [53]; Down-regulated in invasive tumors [66] }\end{array}$ \\
\hline NAV3 & $64 / 42$ & Differentially expressed in hill-type cancer cells [67] \\
\hline
\end{tabular}

Frequency denotes the number of differentially connected edges detected in GSE2990 and GSE6532.

implicated in breast cancer biology suggests that differential connectivity mapping is exquisitely specific in the identification of biologically relevant genes. We note that the 10th gene, DHRS2, though not previously implicated in studies of breast cancer, has been associated with other estrogen-responsive cancer types of the female reproductive tract, such as endometrial and ovarian cancer [32], suggesting that it too is a true positive finding, and represents a novel breast cancer target.

In contrast to more standard statistical methods, more spurious evidence for differential connectivity might be found, paradoxically, in studies of small sample size when true connections in samples from one disease state are not detected due to low statistical power. We thus performed permutation tests to obtain a null distribution of the number of differential connections for each gene in the two disease states. With 500 permutations, two of the ten genes (CXCL13 and MMP12) were rarely observed in both datasets $(0.2 \%$ and $0.4 \%$, respectively), and thus can be considered to be reliable hubs demonstrating consistent differential connectivity by histological grade that are not likely observed due to chance. We further note that although there is a strong curvilinear relationship between the total number of significant connections within a network (based on posterior probability thresholds) and the number of differential connections between states (p-values $\approx 0$, see Figure 6), we observe that both CXCL13 and MMP12 represent outliers in these distributions of both datasets, exhibiting a higher proportion of differential connections even when accounting for the total number of connections. Therefore, they are unlikely to represent false positive results, and represent high priority targets central to breast cancer grade.

We next examined whether these same genes could be identified using more standard analytic approaches (making our method redundant) or whether our approach provides truly independent information. When we applied traditional differential expression analysis (linear regression as implemented in the $\mathrm{R}$ package limma: Linear Models for Microarray Data, [33]) to the datasets, we found that only two of the 10 hub genes AGTR1 and NAV3 - were themselves differentially expressed by histological grade (FDR adjusted p-value $\leq$ 0.05). Moreover, none of the 10 differentially connected hub genes were identified as relevant grade-related genes in the original report by [34]. These comparisons suggest that differential connectivity mapping can identify disease relevant genes that would not be found using more traditional approaches. The lack of differential expression for most of the hubs themselves argues that the observed differential connectivity patterns are not primarily due to primary alterations of hub gene expression, but rather due to more subtle changes in expression of numerous genes interacting with these hubs.

We also individually tested each of 5,452 published gene sets comprising the Molecular Signatures Database [[35], MSigDB,] for evidence of differential connectivity in the breast cancer data set. We considered 2,785 MSigDB gene sets that consist of 5 or more genes represented in the breast cancer analysis, and for 

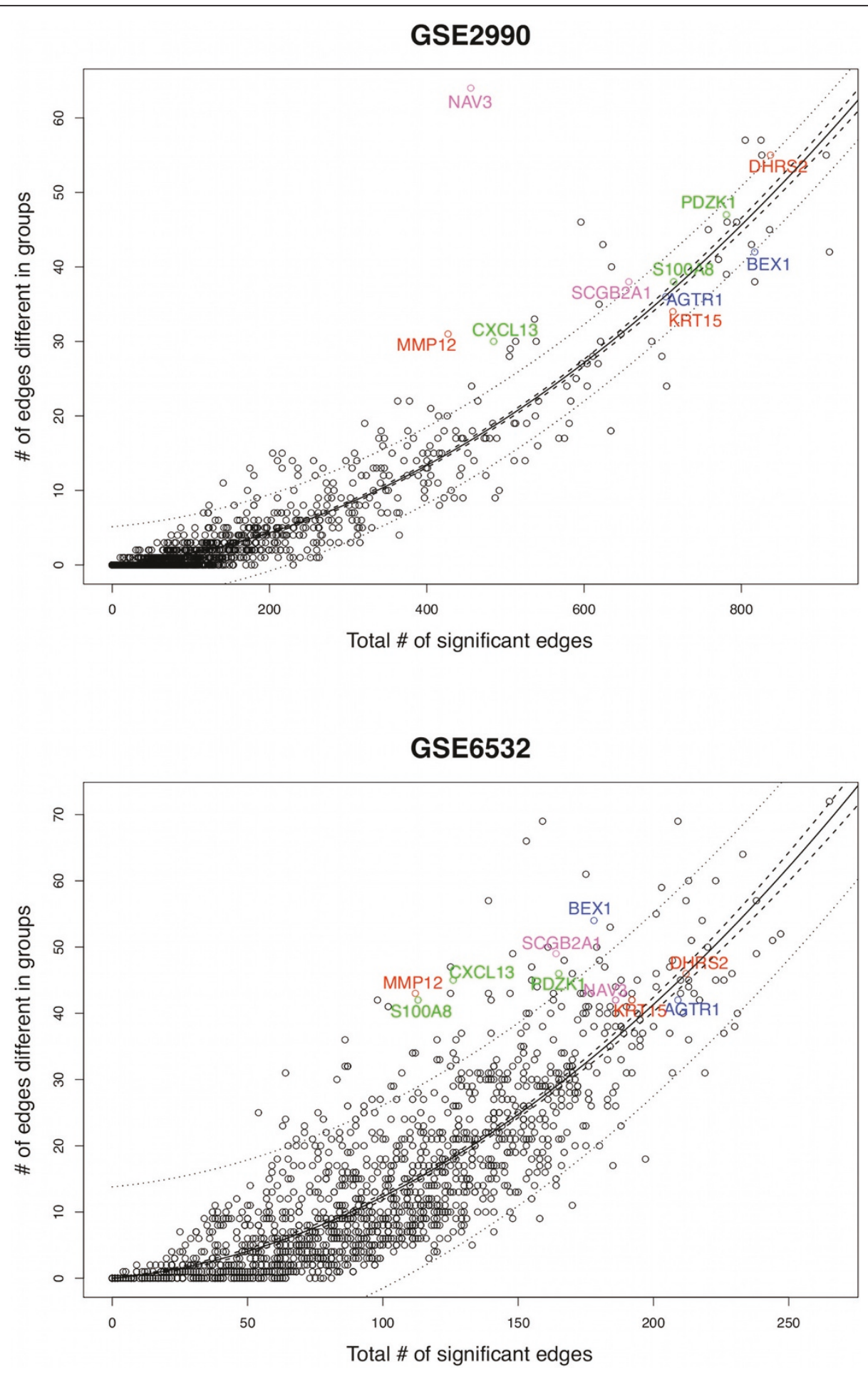

Figure 6 Differential gene connectivity as a function of overall connectivity for two breast cancer datasets. The differential gene connectivity for each gene is the number of genes with which the absolute log posterior oddsratio is greater than 55 for GSE2990 and 35 for GSE6532 (thresholds based on $\sim 0.1 \%$ percentiles of the null distribution from 100 permutations). The overall connectivity is the number of genes with which the posterior probability of connection is over $90 \%$, which represents about $3.5 \%$ of all the edges overall. The solid lines represent the quadratic fitted function and the dashed and dotted lines represent the $95 \%$ confidence and prediction intervals, respectively. The 10 genes with 30 or more differential connections in both datasets are labeled. Note that CXCL13 and MMP12 fall outside the 95\% confidence and prediction intervals in both datasets. 
each gene set we calculated the DC Score. We also performed permutation tests to obtain the null distribution of DC score. DC-scores above the $99 \%$ percentile of the null distributions from 100 permutation sets were observed for 108 and 185 Broad Sets in the GSE2990 and GSE6532 breast cancer datasets, respectively, including 80 Broad Sets that exhibited differential network connectivity in both datasets. Additional file 1 (Table S1) details the 16 Broad Sets that reproducibly demonstrated such extreme differential connectivity in both datasets with at least 3 differential connections in each dataset. Most have been implicated in tumor biology, and many of these gene sets have been implicated in breast cancer progression, including chromosomal region 1p33 [36], matrix metalloproteinases (including MMP12), and sequence targets of peroxisome proliferator-activated receptor alpha $[37,38]$. Potential therapeutic targets were also identified, including subnetworks of the polyunsaturated fatty acid synthesis pathway [39] and of VEGFinduced factors [40] (Figure 7). For example, consistent differential connectivity was noted for a set of genes [[41], Broad Set VEGF_HUVEC_30MIN_UP] upregulated in human umbilical vein endothelial cells (HUVECs) by VEGF, a proangiogenic factors critical to tumor progression and metastasis [40]. The differentially connected sub-network (Figure 7) centers on Cys2-His2 zinc finger transcription factors Early Growth Response 1 and 2 (EGR1 and EGR2). EGR1 and EGR2 directly regulate a series of classical tumor suppressors $[42,43]$, and experimental interference of their expression dramatically alter breast cancer cell growth rates $[44,45]$. Evidence of differential connectivity was observed for numerous additional gene sets implicated in other carcinomas, though not previously with breast cancer. In response to an anonymous reviewer's suggestion, we also ran an analysis on another breast cancer set, GEO series GSE11121 [46] with Affymetrix Human Genome U133A Array to further confirm the reproducibility of our findings. We selected 29 patients with grade 1 breast cancer and 35 grade 3 breast cancer (ER data unavailable), and compared the networks derived from the two subsets. We found 35 hub genes with over 30 differential connections. Five of them overlap with the hub list from GSE2990(CPB1, PRAME, MMP12, BEX1, NAV3), which use the same platform. Three of them (MMP12, BEX1, NAV3) overlap with both GSE2990 and GSE6532 hub lists. The other gene of interest, CXCL13, also has a large number differential connections (28). These results show strong reproducibility in the third data set, demonstrating that the our findings are not due to platform differences.

\section{Discussion}

The appeal of systems-based or interacteome mapping approaches for the study of disease is steadily increasing with the recognition that non-linear epistatic interaction underlies all but the simplest of biological processes. However, formal identification of biologically relevant interaction patterns imbedded in complex network connectivity maps has been a challenging problem. Several studies have looked at global comparison of the networks based on annotated database, such as GO or KEGG [14-16]. Unlike our method, those previous studies assume complete knowledge of the networks (i.e. they do not accommodate uncertainty in the observed connectivity between nodes). In many instances, however, complete certainty is unattainable. Moreover, these methods are largely global, but do not provide information regarding regional differences (i.e. measures of difference in connectivity between any two nodes in the network). Without a measure of variability of the model, it is not easy to distinguish disease-related genes from those that have neutral roles. There are several methods for comparing region differential connectivity between two networks, based on pair-wise gene co-expression relationships, either at the gene cluster/module level $[17,19,47,48]$ or at the individual gene level [18]. Here we have presented a novel approach that enables direct comparison of two different networks derived from Gaussian graphical model. The key feature of the GGM approach is that the network inference is based on partial correlation (i.e. conditional dependence), which distinguishes direct interactions from indirect ones [24,49]. The postORs from empirical Bayes approach provide an easily interpretable quantitative measure for differential connectivity, allowing search for local differential connectivity either for individual genes, gene pairs, or on a cluster/module level. The method performed well in detecting differential network connectivity in simulations of moderate sample size, compared to other simple methods with Pearson correlations or partial correlations only. In fact, even though the sensitivity was modest, both the simulation studies and the real breast cancer datasets suggest that our approach detects many of the strongest associations with very high specificity.

Application of differential connectivity mapping to the breast cancer data sets provides several important insights, both regarding the utility of this approach to other disease states, and with respect to the importance of network connectivity underlying disease processes such as cancer. With regard to the performance of the method, we first found substantial reproducibility ( 30\%) in the observed connectivity patterns across the two breast cancer datasets, then similar results were found in the third data set, suggesting network connectivity as a 


\section{VEGF_HUVEC_30MIN_UP Network}

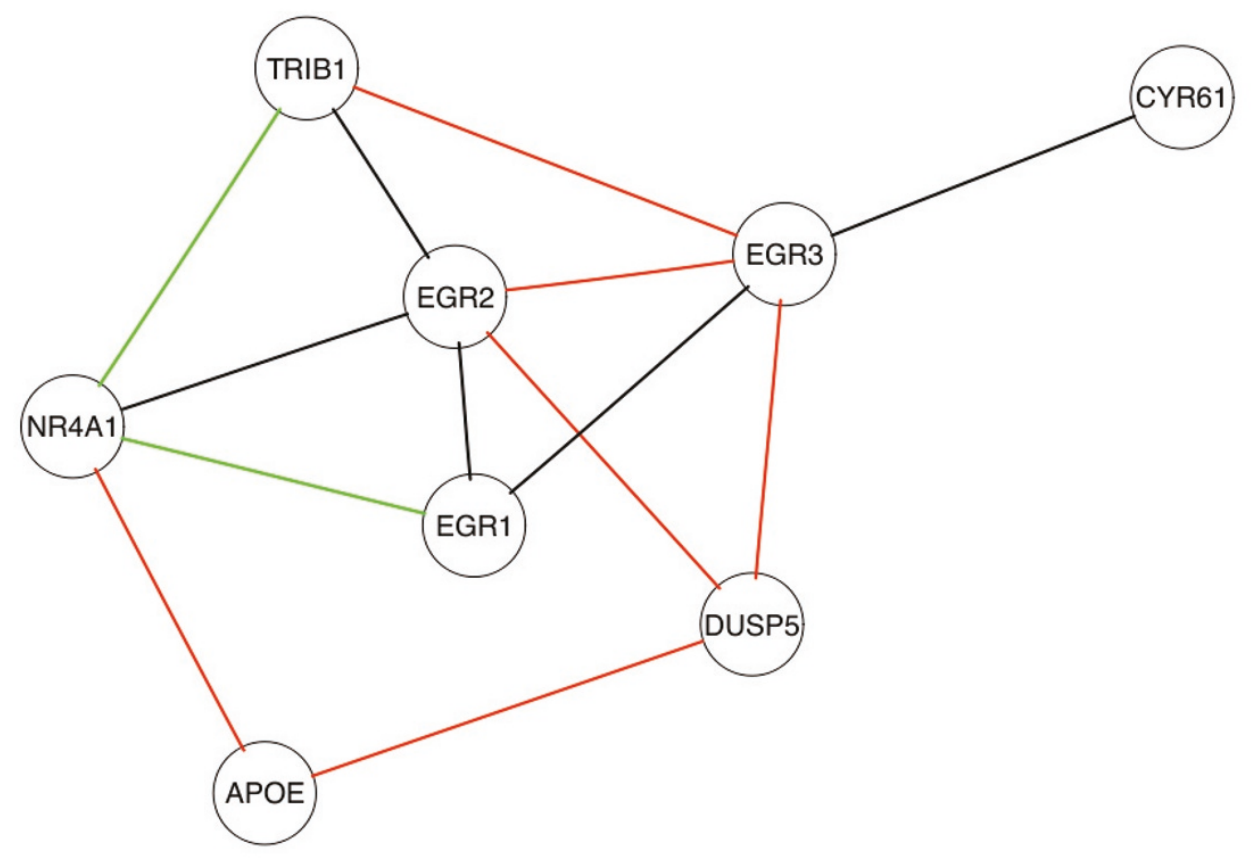

Figure 7 Differentially connected sub-network of the VEGF_HUVEC_30MIN_UP BroadSet. VEGF_HUVEC_30MIN_UP is a collection of 24 transcripts significantly upregulated in human umbilical cord endothelial cells at 30 minutes following treatment with VEGF [41]. Network limited to the 8 of 24 transcripts demonstrating differential connectivity in the two breast cancer datasets. Lines denote differentially connected edges observed in GSE2990 (red), GSE6532 (green), or both (black).

robust, measurable property of complex biological processes. Second, many of the most compelling findings from our analysis (the 10 hubs observed in both datasets) have been previously implicated in breast cancer or other estrogen-responsive cancers, suggesting that the approach is highly specific with regard to biologically relevant findings. Third, as the hubs genes are not always expressed, the majority of the 10 hub genes were not detected using the traditional differential expression approach. Differential connectivity mapping complements differential gene expression analysis and can be used to identify those genes.

Perhaps most importantly, careful review of the specific genes identified suggests that hubs manifesting differential connectivity (or one or more of their connected edges) may represent important candidates for therapeutic targeting. In addition to EGR1 (discussed above), of the 10 hub genes identified, there is experimental evidence for at least three that their targeted manipulation alters the malignant and invasive potential of breast cancer. Matrix metalloprotease 12 (MMP12), a protease that converts plasminogen to angiostatin (a potent inhibitor of angiogenesis), inhibits angiogenesis when overespressed in breast cancer tissue [50]. S100A8, a calciumbinding protein that complexes with S100A9 and whose expression is suppressed by functional BRCA1 [51], is induced by $\mathrm{H}$-Ras to promote malignant potential (tumor cell invasion and migration). Contradictory reports suggest that these malignant properties are either attenuated [52] or enhanced [53] upon siRNAmediated knockdown of S100A8/A9 expression, suggesting S100A8 as a targetable regulator of malignant potential. Similarly, AGTR1 (one of only two differentiallyconnected hubs that was also itself differentially 
expressed across tissue grades) is a potent inducer of invasive phenotypic properties when overexpressed in primary mammary epithelial cells [54]. These effects are inhibited by the AGTR1 antagonist losartan, and FDAapproved medication commonly prescribed for the management of essential hypertension. Consistent with these observations, treatment of xenograft models of breast cancer with losartan reduces tumor growth in AGTR1positive, but not AGTR1-negative, breast cancers [54]. It is intriguing to speculate whether manipulation of NAV3, the only other gene that displayed both properties of differential connectivity and differential expression across tissue grade, would have similar effects in altering the malignant potential of breast cancers.

\section{Conclusion}

In conclusion, we have developed a highly specific method for the identification of genes that demonstrate differential connectivity across disease states. Though applied here to transcriptome data, this method can be applied more broadly to other types of biological network models, and can serve as a novel approach for the identification of high priority target nodes underlying complex biological processes.

\section{Additional material}

Additional file 1: Broad Sets demonstrating differential connectivity by breast cancer histological grade. This table includes the 16 Broad Sets that reproducibly demonstrated significant differential connectivity in both GSE2990 and GSE6532 with at least 3 differential connections in each dataset.

\begin{abstract}
Acknowledgements
The authors acknowledge support of the National Institutes of Health through grants R01 HL086601, RC2 HL101543 and R01 HG003646. The authors would also like to thank the anonymous reviewers for the helpful comments and suggestions.
\end{abstract}

\section{Author details}

'Channing Laboratory, Brigham and Women's Hospital, Harvard Medical School, Boston MA 02115, USA. ${ }^{2}$ Division of Pulmonary and Critical Care Medicine, Brigham and Women's Hospital, Boston MA 02115, USA. ${ }^{3}$ Center for Genomic Medicine, Brigham and Women's Hospital, Boston MA 02115, USA.

\section{Authors' contributions}

The statistical model and methodology were developed by JC based on the concept by JC and BAR. JC carried out the analysis for simulation and breast cancer data with the support of VJC and RL for statistics and bioinformatics. The manuscript was written by JC and BAR and all co-authors have approved the final version.

Received: 24 November 2010 Accepted: 31 May 2011

Published: 31 May 2011

\section{References}

1. Barabási AL, Oltvai ZN: Network biology: understanding the cell's functional organization. Nature Reviews Genetics 2004, 5:101-113.
2. Törönen P, Kolehmainen M, Wong G, Castrén E: Analysis of gene expression data using self-organizing maps. FEBS Lett 1999, 451(2):142-146.

3. Li S, Armstrong CM, Bertin N, Ge H, Milstein S, Boxem M, Vidalain PO, Han JD, Chesneau A, Hao T, Goldberg D, Li N, Martinez M, Rual JF, Lamesch P, Xu L, Tewari M, Wong SL, Zhang LV, Berriz GF, Jacotot L, Vaglio P, Reboul J, Hirozane-Kishikawa T, Li Q, Gabel HW, Elewa A, Baumgartner B, Rose DJ, Yu H, Bosak S, Sequerra R, Fraser A, Mango SE, Saxton WM, Strome S, Van Den Heuvel S, Piano F, Vandenhaute J, Sardet C, Gerstein M, Doucette-Stamm L, Gunsalus KC, Harper JW, Cusick ME, Roth $F P$, Hill DE, Vidal M: A map of the interactome network of the metazoan C. elegans. Science 2003, 303:540-543.

4. Yu H, Braun P, Yildirim M, Lemmens I, Venkatesan K, Sahalie J, HirozaneKishikawa T, Gebreab F, Li N, Simonis N, Hao T, Rual JF, Dricot A, Vazquez A, Murray RR, Simon C, Tardivo L, Tam S, N S, Fan C, de Smet AS, Motyl A, Hudson ME, Park J, Xin X, Cusick M, Moore T, Boone C, Snyder M, Roth FP, L BA, Tavernier J, Hill DE, Vidal M: High-quality binary protein interaction map of the yeast interactome network. Science 2008, 322(5898):104-110.

5. Jeong H, Tombor B, Albert R, Oltvai ZN, Barabási AL: The large-scale organization of metabolic networks. Nature 2000, 407:651-654.

6. Mani KM, Lefebvre C, Wang K, Lim WK, Basso K, Dalla-Favera R, Califano A: A systems biology approach to prediction of oncogenes and molecular perturbation targets in B-cell lymphomas. Mol Syst Biol 2008, 4(169).

7. Hernández P, Huerta-Cepas J, Montaner D, Al-Shahrour F, Valls J, Gómez L, Capellá G, Dopazo J, Pujana MA: Evidence for systems-level molecular mechanisms of tumorigenesis. BMC Genomics 2007, 20(185).

8. Rhodes DR, Chinnaiyan AM: Integrative analysis of the cancer transcriptome. Nat Genet 2005, 37(Suppl):S31-37.

9. Lim J, Hao T, Shaw C, Patel AJ, Szabó G, Rual JF, Fisk CJ, Li N, Smolyar A Hill $D E$, L BA, Vidal M, Zoghbi HY: A protein-protein interaction network for human inherited ataxias and disorders of Purkinje cell degeneration. Cell 2006, 125(4):645-647.

10. Duncan SA, Navas MA, Dufort D, Rossant J, Stoffel M: Regulation of a transcription factor network required for differentiation and metabolism. Science 1998, 281(5377):692-695.

11. Chen Y, Zhu J, Lum PY, Yang X, Pinto S, MacNeil DJ, Zhang C, Lamb J, Edwards S, Sieberts SK, Leonardson A, Castellini LW, Wang S, Champy MF, Zhang B, Emilsson V, Doss S, Ghazalpour A, Horvath S, Drake TA, Lusis AJ, Schadt EE: Variations in DNA elucidate molecular networks that cause disease. Nature 2008, 452(7186):429-435.

12. Ghazalpour A, Doss S, Zhang B, Wang S, Plaisier C, Castellanos R, Brozell A, Schadt EE, Drake TA, Lusis AJ, Horvath S: Integrating genetic and network analysis to characterize genes related to mouse weight. PLos Genet 2006, 2(8):e130.

13. de la Fuente A: From 'differential expression' to 'differential networking' identification of dysfunctional regulatory networks in diseases. Trends in Genetics 2010, 26(7):326-333.

14. Brun M, Kim S, Choi W, Dougherty ER: Comparison of gene regulatory networks via steady-state trajectories. EURASIP Journal on Bioinformatics and Systems Biology 2007, 2007(82702).

15. Chor B, Tuller T: Biological networks: comparison, conservation, and evolution via relative description length. J Comp Biol 2007, 14(6):817-838.

16. Narayanan M, Karp RM: Comparing protein interaction networks via a graph match-and-split algorithm. J Comp Biol 2007, 14(7):892-907.

17. Ihmels J, Bergmann S, Berman J, Barkai N: Comparative gene expression analysis by differential clustering approach: application to the Candida albicans transcription program. PLos Genet 2005, 1(3):e39..

18. Choi J, Yu U, Yoo OJ, Kim S: Differential coexpression analysis using microarray data and its application to human cancer. Bioinformatics 2005, 21(24):4348-4355.

19. Southworth LK, Owen AB, Kim SK: Aging Mice Show a Decreasing Correlation of Gene Expression within Genetic Modules. PLos Genet 2009, 5(12):e1000776.

20. Kishino $\mathrm{H}$, Waddell P: Correspondence analysis of genes and tissue types and finding genetic links from microarray data. Genome Informatics 2000, 11:83-95.

21. Toh H, Horimoto K: System for Automatically Inferring a Genetic Netwerk from Expression Profiles. J Biol Phys 2002, 28(3):449-464

22. Wu X, Ye Y, Subramanian KR: Interactive Analysis of Gene Interactions Using Graphical Gaussian Model. Proceedings of the ACM SIGKDD Workshop on Data Mining in Bioinformatics 2003, 3:63-69. 
23. Dobra A, Hans C, Jones B, Nevins JR, Yao G, West M: Sparse graphical models for exploring gene expression data. J Multiv Anal 2004, 90:196-212.

24. Schäfer J, Strimmer K: An empirical Bayes approach to inferring largescale gene association networks. Bioinformatics 2005, 21(6):754-764.

25. Chu J, Weiss ST, Carey VJ, Raby BA: A graphical model approach for inferring large-scale networks integrating gene expression and genetic polymorphism. BMC Systems Biology 2009, 3(55)

26. Schäfer J, Strimmer K: A shrinking approach to large-scale covariance matrix estimation and implications for functional genomics. Statist Appl Genet Mol Biol 2007, 4(32)

27. Reverter A, Ingham A, Lehnert SA, Tan SH, Wang Y, Ratnakumar A, Dalrymple BP: Simultaneous identification of differential gene expression and connectivity in inflammation, adipogenesis and cancer. Bioinformatics 2006, 22(19):2396-2404.

28. Sotiriou $C$, Neo S, McShane LM, Korn EL, Long PM, Jazaeri A, Martiat $P$, Fox SB, Harris AL, Liu ET: Breast cancer classification and prognosis based on gene expression profiles from a population-based study. Proc Nat Aca Sci 2003, 100(18):10393-10398.

29. Loi S, Haibe-Kains B, Desmedt C, Wirapati P, Lallemand F, Tutt AM, Gillet C, Ellis P, Ryder K, Reid JF, Daidone MG, Pierotti MA, Berns EM, Jansen MP, Foekens JA, Delorenzi M, Bontempi G, Piccart MJ, Sotiriou C: Predicting prognosis using molecular profiling in estrogen receptor-positive breast cancer treated with tamoxifen. BMC Genomics 2008, 9(239).

30. Gentleman R, Carey V, Huber W, Hahne F: Using the genefilter function to filter genes from a microarray dataset. 2011 [http://www.bioconductor. org/packages/2.8/bioc/html/genefilter.html].

31. Bourgon R, Gentleman R, Huber W: Independent filtering increases detection power for high-throughput experiments. Proc Natl Acad Sci 2010, 107(21):9546-9551

32. Song J, Shih IM, Chan D, Zhang Z: Suppression of annexin A11 in ovarian cancer: implications in chemoresistance. Neoplasia 2009, 11(6):605-614.

33. Smyth GK: Linear models and empirical Bayes methods for assessing differential expression in microarray experiments. Statistical Applications in Genetics and Molecular Biology 2004, 3:3.

34. Sotiriou C, Wirapati $P$, Loi S, Harris A, Fox S, Smeds J, Nordgren H, Farmer $P$, Praz V, Haibe-Kains B, Desmedt C, Larsimont D, Cardoso F, Peterse H, Nuyten D, Buyse M, de Vijver MJV, Bergh J, Piccart M, Delorenzi M: Gene expression profiling in breast cancer: understanding the molecular basis of histologic grade to improve prognosis. J Natl Cancer Inst 2006, 98(4):262-272

35. Subramanian A, Tamayo P, Mootha VK, Mukherjee S, Ebert BL, Gillette MA, Paulovich A, Pomeroy SL, Golub TR, Lander ES, Mesirov JP: Gene set enrichment analysis: A knowledge-based approach for interpreting genome-wide expression profiles. Proc Nat Aca Sci 2005, 102(43):15545-15550.

36. Borg A, Zhang QX, Olsson H, Wenngren E: Chromosome 1 alterations in breast cancer: allelic loss on $1 \mathrm{p}$ and $1 \mathrm{q}$ is related to lymphogenic metastases and poor prognosis. Genes Chromosomes Cancer 1992, 5(4):311-320.

37. Suchanek KM, May FJ, Robinson JA, Lee WJ, Holman NA, Monteith GR, Roberts-Thomson SJ: Peroxisome proliferator-activated receptor alpha in the human breast cancer cell lines MCF-7 and MDA-MB-231. Mol Carcinog 2002, 34(4):165-171.

38. Bocca C, Bozzo F, Martinasso G, Canuto RA, Miglietta A: Involvement of PPARalpha in the growth inhibitory effect of arachidonic acid on breast cancer cells. Br J Nutr 2008, 100(4):739-750.

39. Pizer ES, Jackisch C, Wood FD, Pasternack GR, Davidson NE, Kuhajda FP. Inhibition of fatty acid synthesis induces programmed cell death in human breast cancer cells. Cancer Res 1996, 56(12):2745-2747.

40. Folkman J: Angiogenesis in cancer, vascular, rheumatoid and other disease. Nat Med 1995, 1:27-31

41. Abe M, Sato $Y$ : cDNA microarray analysis of the gene expression profile of VEGF-activated human umbilical vein endothelial cells. Angiogenesis 2001, 4(4):289-298

42. Baron V, Adamson ED, Calogero A, Ragona G, Mercola D: The transcription factor Egr1 is a direct regulator of multiple tumor suppressors including TGFbeta1, PTEN, p53, and fibronectin. Cancer Gene Ther 2006, 13(2):115-124

43. Dillon RL, Brown ST, Ling C, Shioda T, Muller WJ: An EGR2/CITED1 transcription factor complex and the 14-3-3sigma tumor suppressor are involved in regulating ErbB2 expression in a transgenic-mouse model of human breast cancer. Mol Cell Biol 2007, 27(24):8648-8657.

44. Fahmy R, Dass CR, Sun LQ, Chesterman CN, Khachigian LM: Transcription factor Egr-1 supports FGF-dependent angiogenesis during neovascularization and tumor growth. Nat Med 2003, 9(8):1026-1032.

45. Unoki M, Nakamura Y: Growth-suppressive effects of BPOZ and EGR2, two genes involved in the PTEN signaling pathway. Oncogene 2001 20(33):4457-4465.

46. Schmidt M, Böhm D, von Törne C, Steiner E, Puhl A, Pilch H, Lehr HA, Hengstler JG, Kölbl H, Gehrmann M: The Humoral Immune System Has a Key Prognostic Impact in Node-Negative Breast Cancer. Cancer Res 2008 68(13):5405-5413.

47. Watson M: CoXpress: differential co-expression in gene expression data. BMC Bioinformatics 2006, 7(509)

48. Choi $Y$, Kendziorski C: Statistical methods for gene set co-expression analysis. Bioinformatics 2009, 25(21):2780-2786

49. Reverter A, Chan EKF: Combining partial correlation and an information theory approach to the reversed engineering of gene co-expression networks. Bioinformatics 2008, 24(21):2491-2497.

50. Margheri F, Serrati S, Lapucci A, Anastasia C, Giusti B, Pucci M, Torre E, Bianchini F, Calorini L, Albini A, Ventura A, Fibbi G, Del Rosso M: Systemic sclerosis-endothelial cell antiangiogenic pentraxin 3 and matrix metalloprotease 12 control human breast cancer tumor vascularization and development in mice. Neoplasia 2009, 11(10):1106-1115.

51. Kennedy RD, Gorski JJ, Quinn JE, Stewart GE, James CR, Moore S, Mulligan K, Emberley ED, Lioe TF, Morrison PJ, Mullan PB, Reid G, Johnston PG, Watson PH, Harkin DP: BRCA1 and c-Myc Associate to Transcriptionally Repress Psoriasin, a DNA Damage-Inducible Gene. Cancer Res 2005, 65(22):10265-10272.

52. Moon A, Yong HY, Song Jl, Cukovic D, Salagrama S, Kaplan D, Putt D, Kim H, Dombkowski A, Kim HR: Global gene expression profiling unveils S100A8/A9 as candidate markers in H-ras-mediated human breast epithelial cell invasion. Mol cancer Res 2008, 6(10):1544-1553.

53. Rhee DK, Park SH, Jang YK: Molecular signatures associated with transformation and progression to breast cancer in the isogenic MCF10 model. Genomics 2008, 92(6):419-428.

54. Rhodes DR, Ateeg B, Cao Q, Tomlins SA, Mehra R, Laxman B, KalyanaSundaram S, Lonigro RJ, Helgeson BE, Bhojani MS, Rehemtulla A, Kleer CG, Hayes DF, Lucas PC, Varambally S, Chinnaiyan AM: AGTR1 overexpression defines a subset of breast cancer and confers sensitivity to losartan, an AGTR1 antagonist. Proc Nat Aca Sci 2009, 106(25):10284-10289.

55. Monge M, Colas E, Doll A, Gil-Moreno A, Castellvi J, Diaz B, Gonzalez M, Lopez-Lopez R, Xercavins J, Carreras R, Alameda F, Canals F, Gabrielli F, Reventos J, Abal M: Proteomic approach to ETV5 during endometrial carcinoma invasion reveals a link to oxidative stress. Carcinogenesis 2009, 30(8):1288-1297

56. Panse J, Friedrichs K, Marx A, Hildebrandt Y, Luetkens T, Barrels K, Horn C, Stahl T, Cao Y, Milde-Langosch K, Niendorf A, Kröger N, Wenzel S, Leuwer R, Bokemeyer C, Hegewisch-Becker S, Atanackovic D: Chemokine CXCL13 is overexpressed in the tumour tissue and in the peripheral blood of breast cancer patients. Br J Cancer 2008, 99(6):930-938.

57. Folgueira MA, Brentani $H$, Katayama ML, Patrão DF, Carraro DM, Mourão Netto M, Barbosa EM, Caldeira JR, Abreu AP, Lyra EC, Kaiano JH, Mota LD, Campos AH, Maciel MS, Dellamano M, Caballero OL, Brentani MM: Gene expression profiling of clinical stages II and III breast cancer. Braz J Med Biol Res 2006, 39(8):1101-1113.

58. Cimino D, Fuso L, Sfiligoi C, Biglia N, Ponzone R, Maggiorotto F, Russo G, Cicatiello L, Weisz A, Taverna D, Sismondi P, De Bortoli M: Identification of new genes associated with breast cancer progression by gene expression analysis of predefined sets of neoplastic tissues. Int J Cancer 2008, 123(6):1327-1338.

59. Watson MA, Fleming TP: Isolation of differentially expressed sequence tags from human breast cancer. Cancer Res 1994, 54(17):4598-4602.

60. Watson MA, Fleming TP: Mammaglobin, a mammary-specific member of the uteroglobin gene family, is overexpressed in human breast cancer. Cancer Res 1996, 56(4):860-865.

61. Maras M, Vanparys C, Muylle F, Robbens J, Berger U, Barber JL, Blust R, De Coen W: Estrogen-like properties of fluorotelomer alcohols as revealed by mcf-7 breast cancer cell proliferation. Environ Health Perspect 2006, 114:100-105 
62. Ghosh MG, Thompson DA, Weigel RJ: PDZK1 and GREB1 are estrogenregulated genes expressed in hormone-responsive breast cancer. Cancer Res 2003, 60(22):6367-6375.

63. Mackay A, Urruticoechea A, Dixon JM, Dexter T, Fenwick K, Ashworth A, Drury S, Larionov A, Young O, White S, Miller WR, Evans DB, Dowsett M: Molecular response to aromatase inhibitor treatment in primary breast cancer. Breast Cancer Res 2007, 9(3):R37..

64. Naderi AEA, Teschendorff, Beigel J, Cariati M, Ellis IO, Brenton JD, Caldas C: BEX2 is overexpressed in a subset of primary breast cancers and mediates nerve growth factor/nuclear factor-kappaB inhibition of apoptosis in breast cancer cell lines. Cancer Res 2007, 67(14):6725-6736.

65. Arai K, Takano S, Teratani T, Ito Y, Yamada T, Nozawa R: S100A8 and S100A9 overexpression is associated with poor pathological parameters in invasive ductal carcinoma of the breast. Curr Cancer Drug Targets 2008, 8(4):243-252.

66. Nagaraja G, Othman M, Fox B, Alsaber R, Pellegrino C, Zeng Y, Khanna R, Tamburini P, Swaroop A, Kandpal R: Gene expression signatures and biomarkers of noninvasive and invasive breast cancer cells: comprehensive profiles by representational difference analysis, microarrays and proteomics. Oncogene 2006, 25(16):2328-2338.

67. Bleeker FE, Lamba S, Rodolfo M, Scarpa A, Leenstra S, Vandertop WP, Bardelli A: Mutational profiling of cancer candidate genes in glioblastoma, melanoma and pancreatic carcinoma reveals a snapshot of their genomic landscapes. Hum Mutat 2009, 30(2):451-459.

doi:10.1186/1752-0509-5-89

Cite this article as: Chu et al: Quantifying differential gene connectivity between disease states for objective identification of disease-relevant genes. BMC Systems Biology 2011 5:89.

\section{Submit your next manuscript to BioMed Central and take full advantage of:}

- Convenient online submission

- Thorough peer review

- No space constraints or color figure charges

- Immediate publication on acceptance

- Inclusion in PubMed, CAS, Scopus and Google Scholar

- Research which is freely available for redistribution

Submit your manuscript at www.biomedcentral.com/submit 